\title{
Peripheral oxygen transport in skeletal muscle of Antarctic and sub-Antarctic notothenioid fish
}

\author{
S. Egginton ${ }^{1}$, , C. Skilbeck ${ }^{1}$, L. Hoofd ${ }^{2}$, J. Calvo ${ }^{3}$ and I. A. Johnston ${ }^{4}$ \\ ${ }^{1}$ Department of Physiology, University of Birmingham, Birmingham B15 2TT, UK, ${ }^{2}$ Department of Physiology, \\ University of Nijmegen, 6525 Nijmegen, The Netherlands, ${ }^{3}$ CONICET, CADIC, Ushuaia, Argentina and ${ }^{4}$ School of \\ Biology, Gatty Marine Laboratory, University of St Andrews, Fife KY16 8LB, Scotland \\ *e-mail: s.egginton@bham.ac.uk
}

Accepted 7 January 2002

\begin{abstract}
Summary
Transcellular oxygen flux was modelled mathematically in the aerobic skeletal muscles of perciform fish species living at widely different temperatures (Antarctica, subAntarctica and the Mediterranean Sea). Using structural data derived from stereological analysis of electron micrographs, mean fibre $P_{\mathrm{O}_{2}}$ was calculated on the basis of temperature-corrected rates of mitochondrial respiration and oxygen diffusion. The mean muscle fibre diameter (MFD) among Antarctic notothenioids was in the range $17-61 \mu \mathrm{m}$ and mitochondrial volume density, $V \mathbf{v}($ mit,f), was $0.27-0.53$, but capillary-to-fibre ratio varied only between 1.2 and 1.5. For a mean capillary $P_{\mathrm{O}_{2}}$ of $6 \mathrm{kPa}$, the model predicted a mean tissue $\mathrm{PO}_{2}$ in the range $0.7-5.8 \mathrm{kPa}$ at the estimated maximum aerobic capacity $\left(\dot{M}_{O_{2} \max }\right)$. The lowest levels of tissue oxygenation were found in the pectoral muscle fibres of the icefish Chaenocephalus aceratus, which lacks the respiratory pigments haemoglobin and myoglobin. Red-blooded notothenioids found in the sub-Antarctic had a similar muscle fine structure to those caught south of the

$V v(m i t, f), 56 \mu \mathrm{m}$ and 0.51 , respectively, was calculated to exceed $1 \mathrm{kPa}$ at winter temperatures $\left(4^{\circ} \mathrm{C}\right)$, although oxidative metabolism was predicted to be impaired at the summer maximum of $10^{\circ} \mathrm{C}$. At the high end of the thermal range, related perciform species from the Mediterranean had a negligible drop in intracellular $\boldsymbol{P}_{\mathrm{O}_{2}}$ across their small-diameter fibres, to a minimum of $5.4 \mathrm{kPa}$, comparable with that predicted for Trematomus newnesi from the Antarctic $(5.6 \mathrm{kPa})$ with a similar MFD. These data suggest that, within a single phylogenetic group, integrative structural adaptations potentially enable a similar degree of tissue oxygenation over a $20^{\circ} \mathrm{C}$ range of environmental temperature in the red-blooded notothenioids, and that this is compromised by the lack of respiratory pigments in the icefishes. The mean capillary radius was $\mathbf{1 . 5}$ times greater in the two icefish than in the other notothenioids, and the model simulations indicate that the evolution of wide-bore capillaries is essential to maintain tissue oxygenation in the absence of respiratory pigments.
\end{abstract} Antarctic Convergence, with an MFD of 20-41 $\mu \mathrm{m}$ and $V \mathrm{v}\left(\right.$ mit,f) of $0.27-0.33$, resulting in an estimated mean $P_{\mathrm{O}_{2}}$

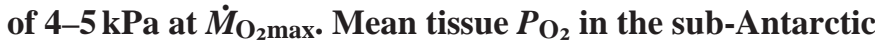
icefish Champsocephalus esox, with greater MFD and

Key words: diffusion, icefish, mathematical model, oxygen tension, stereology, notothenioid fish.

\section{Introduction}

Species of the suborder Notothenioidei dominate the fish fauna of the Southern Ocean, although their relationship to other perciform species is obscure because of the paucity of the fossil record (Eastman, 1993). The notothenioids are Antarctic specialists: of 120 species, 95 are endemic to Antarctic waters, a consequence of rapid radiation following their initial invasion (Clarke and Johnston, 1996). This suborder dominates the icthyofauna of shallow coastal waters in terms of species numbers and biomass. They comprise the bulk of the biomass of the region and are often the only fish species caught in shallow coastal waters; hence, most research has been conducted on this one group of animals.

Notothenioids show some remarkable adaptations to life in sub-zero temperatures, including the production of plasma glycopeptide antifreezes (for a review, see Eastman, 1993). Members of the family Channichthyidae are particularly striking in that they lack functionally significant quantities of the respiratory pigments haemoglobin and skeletal muscle myoglobin, although some species have retained myoglobin expression in the myocardium (Moylan and Sidell, 2000). Oxygen-carrying capacity is thus impaired, with arterial oxygen content only approximately $10 \%$ that in the redblooded Notothenidae (Holeton, 1972; Egginton, 1994). For oxygen supply within the tissues, the oxygen partial pressure is the important variable so, as long as oxygen supply is maintained, capillary $P_{\mathrm{O}_{2}}$ will not be impaired and muscle 
function should not therefore be compromised. However, the extent to which other cardiovascular and structural adaptations compensate to minimise impaired peripheral oxygen transport is unclear.

The Southern Ocean offers a uniquely stable thermal environment within which cold adaptation of fishes may be expected to have occurred, obviating the need to retain the functional plasticity required in more variable ecosystems (Somero, 1995). Specifically, the annual range of the inshore marine environment is only approximately -1.5 to $+1.5^{\circ} \mathrm{C}$. In deep water, which occurs closer than around other continents, temperature hardly varies from around the freezing point of sea water, $-1.86^{\circ} \mathrm{C}$ (Eastman, 1993). The notothenioids were presumably part of the ancestral fauna associated with habitats of the continental shelf during its southerly tectonic movement prior to cooling of the Southern Ocean. However, physical isolation caused by the opening of the Drake Passage and establishment of the circumpolar current has provided the potential for unique features resulting from endemic speciation, which molecular evidence suggests is a relatively recent event (Clarke and Johnston, 1996). What might at first appear to be a cold adaptation might instead be a specialisation or ancestral characteristic of the notothenioids.

Many Antarctic fishes use a labriform type of sustained swimming, making use of well-developed pectoral fins and associated muscles (Archer and Johnston, 1987). Resting metabolic rates are low compared with temperate species, and the factorial scopes for aerobic activity are modest (Wells, 1987; Forster et al., 1987; Johnston et al., 1991). Johnston et al. (1998) found that the temperature-dependence of state 3 respiration of isolated mitochondria in perciform species fitted a single quadratic relationship irrespective of habitat temperature. This indicated that the rate of oxygen consumption per unit mitochondrion volume was relatively fixed and that increasing the volume of mitochondrial clusters was the primary mechanism for enhancing the muscle aerobic capacity in cold-water fish. Indeed, ultrastructural studies have found high densities of mitochondria in the slow muscle of Antarctic fish $[35.6 \%$ in juvenile Notothenia neglecta (Johnston and Camm, 1987), 50.1\% in adult Chaenocephalus aceratus (Johnston, 1987) and $45 \%$ in Psilodraco breviceps (Archer and Johnston, 1991)] approaching or even exceeding those for myocardium of active endotherms (finch $34 \%$, mouse $37 \%$ ) (Bossen et al., 1978). Cold acclimation also results in an increase in mitochondrial volume density in the muscle of many temperate fish species (Johnston and Maitland, 1980; Egginton and Sidell, 1989). Thus, differences in muscle mitochondrial content in Antarctic notothenioids may be related to their phyletic derivation or simply be an extension of the response observed during winter in temperate fishes (cold acclimatisation) that has become fixed in the genome (cold adaptation).

One striking feature of muscle structure in Antarctic notothenioids is the presence of very large diameter fibres; the fibres can exceed $50 \mu \mathrm{m}$ in diameter in aerobic muscles and $500 \mu \mathrm{m}$ in fast muscles (Kilarski et al., 1982; Battram and
Johnston, 1991; Fernandez et al., 2000). Similar large-diameter muscle fibres are also found in notothenioid species from the Beagle Channel living at much higher temperatures (Johnston et al., 1998; Fernandez et al., 2000). The potential problems with oxygen transport in cold-water notothenioids are therefore accentuated by long diffusion distances, which are well beyond those normally experienced in cold-acclimated fishes (Egginton, 1998). To investigate this further, we have compiled data on the fine structure of slow muscle fibres from the locomotory (pectoral) muscle of perciform species inhabiting a wide range of environmental temperatures from the Southern Ocean to the Mediterranean Sea and used a modelling approach to examine the fundamental structural features necessary for adequate oxygenation of skeletal muscle in different thermal environments.

\section{Materials and methods \\ Animals}

The fish species studied all belonged to the Order Perciformes. The Antarctic notothenioids Trematomus newnesi (Boulenger) 9-12 cm standard length (SL) and 5-24 g body mass $\left(M_{\mathrm{b}}\right) \quad(N=5)$, Lepidonotothen nudifrons (Lönnberg) 12-14 cm SL and 30-50 g Mb $(N=5)$ and Notothenia coriiceps (Richardson) 30-37 cm SL and 550-1050 g $M_{\mathrm{b}}(N=6)$ and the channichthyid Chaenocephalus aceratus (Lönnberg) $42-52 \mathrm{~cm}$ SL and 615-1470 g $M_{\mathrm{b}}(N=6)$ were caught around the South Orkney Islands $\left(60^{\circ} 43^{\prime} \mathrm{S}, 45^{\circ} 36^{\prime} \mathrm{W}\right)$ during the austral summer when sea temperatures are typically -1.0 to $0^{\circ} \mathrm{C}$. The subAntarctic notothenioids Paranotothenia magellanica (Forster) $13-16 \mathrm{~cm}$ SL and 37-69 g $M_{\mathrm{b}}(N=5)$, Eleginops maclovinus (Valenciennes) 14-17 cm SL and 39-76g $M_{\mathrm{b}}(N=5)$ and Patagonotothen tessellata (Richardson) $17-20 \mathrm{~cm} \mathrm{SL}$ and 69-103 g $M_{\mathrm{b}}(N=5)$ and the icefish Champsocephalus esox (Günther) 23-25 cm SL and 75-90 g $M_{\mathrm{b}}(N=5)$ were caught in the Beagle Channel, Argentina, where winter temperatures are around $4{ }^{\circ} \mathrm{C}$ and summer temperatures reach $10-11^{\circ} \mathrm{C}$. The Mediterranean perciform species used for comparison were Lithognathus mormyrus L., 12-15 cm SL and 38-63 g $M_{\mathrm{b}}$ $(N=5)$, and Coris julius L., 9-14 cm SL and 6-23 g $M_{\mathrm{b}}(N=4)$, which were caught in the Bay of Naples during the autumn, where temperatures were around $20^{\circ} \mathrm{C}$.

\section{Sample preparation}

Four to six fish were selected at random from each group and briefly sedated in bicarbonate buffered 1:50000 (m/v) tricaine methane sulphonate (MS222; Sandoz) prior to stunning and spinal cord transection. The pectoral muscles deliver the main propulsive force during swimming, with slow ('red') fibres located mainly adjacent to the pectoral girdle. Samples of the slow adductor muscle were dissected free from skin, subdermal lipid and overlying fast muscle. Muscle was pinned at resting length to strengthened cork strips and fixed for $2-3 \mathrm{~h}$ at approximately $10^{\circ} \mathrm{C}$ in a buffered glutaraldehyde solution (Egginton and Sidell, 1989; Archer and Johnston, 1991). Samples were then trimmed into pieces with a cut face of 
approximately $1 \mathrm{~mm}^{2}$, stored overnight in fresh fixative at $4{ }^{\circ} \mathrm{C}$ then post-fixed in buffered $1 \% \mathrm{OsO}_{4}(\mathrm{~m} / \mathrm{v})$ for $1 \mathrm{~h}$, dehydrated in ascending grades of alcohols and vacuum-embedded in epoxy resin (Araldite/Epon). Six blocks per fish were prepared, and one was chosen at random for subsequent analysis.

\section{Light microscopy}

Semi-thin $(0.5 \mu \mathrm{m})$ sections were stained with Toluidine Blue to orientate the blocks for true transverse or longitudinal sections of muscle fibres (around 50 per field, two fields per section) and to quantify the capillary supply at a magnification of $\times 500$ as capillary-to-fibre ratio (C:F), using an unbiased sampling rule (Egginton, 1990) and rounded to the nearest half-capillary for ease of computation. Mean fibre area was estimated as the inverse of fibre density per field or as the mean of digitised areas (previous experience has shown these approaches to produce equivalent values).

\section{Electron microscopy}

Ultrathin (approximately $80 \mathrm{~nm}$ ) sections (one per block, chosen at random) were double-stained with methanoic uranyl acetate $(30 \% \mathrm{~m} / \mathrm{v})$ and aqueous lead tartrate $(2 \%)$, and electron micrographs were taken at an accelerating voltage of $60 \mathrm{kV}$ from one or two grids per block (one field per grid, 20-30 fibres per field). Micrographs were analysed at a final magnification of $\times 8750$ to $\times 15750$ using the transparent overlay of a stereological counting grid. A lattice spacing $(d)$ of $1.3 \mathrm{~cm}$ (equivalent to $0.8-1.51 \mu \mathrm{m}$ ) was used for quantification of subcellular structure using standard pointcounting and line-intercept techniques for area and boundary length estimates, respectively (Egginton and Sidell, 1989). Providing that random sampling criteria are applied, volume density $(V \mathrm{v})$ in practice represents the area of any structure as a proportion of a reference cross-sectional area. The large fibre diameter precluded the use of the whole cross section as reference phase, so muscle was subsampled by the method of systematic area-weighted quadrats, whereby different regions are sampled in proportion to their volume fraction, giving an unbiased estimate of population means (Cruz-Orive and Weibel, 1981). Data were collected separately for subsarcolemmal and intermyofibrillar zones, from which mean fibre volumes could also be calculated.

\section{Mathematical modelling}

The combined effect that differences in fine structure have on the intracellular oxygen tension of the aerobic pectoral muscle fibres was explored by means of a mathematical model of intracellular diffusion (Hoofd and Egginton, 1997). This model is based on the structural parameters affecting both oxygen delivery and consumption and, hence, provides an estimate of the potential for intracellular oxygenation assuming maximal blood flow and mitochondrial respiration. Briefly, the potential oxygen delivery (determined by the capillary supply) is balanced by oxygen consumption (scaled according to mitochondrial volume), allowing for the diffusion distance involved (which varies with fibre radius) and oxygen permeability (given by the ratio of intracellular lipid to aqueous sarcoplasm), corrected for the kinetic effects of temperature $\left(\mathrm{Q}_{10}\right)$, and partitioned among the distinct structural regions found in fish muscle fibres (subsarcolemmal and intermyofibrillar zones).

The input variables used, and adjusted in an iterative manner to explore their relative importance, were: temperature $\left({ }^{\circ} \mathrm{C}\right)$, oxygen permeability, $p_{\mathrm{O}_{2}}\left(\mathrm{~mol} \mathrm{~m}^{-1} \mathrm{kPa}^{-1} \mathrm{~s}^{-1}\right)$, rate of oxygen consumption, $\dot{M}_{\mathrm{O}_{2}}\left(\mathrm{~mol} \mathrm{O}_{2} \mathrm{~m}^{-3}\right.$ tissue $\left.\mathrm{s}^{-1}\right)$, intermyofibrillar zone radius/fibre radius, mitochondrial volume density, $V v($ mit,f), lipid volume density, $V v($ lip,f), the number of capillaries around a fibre and the angular location of capillaries around a fibre.

The model of necessity invokes a number of assumptions: (i) that muscle fibres have a circular cross section and a radius equal to the mean radius for that tissue, derived from empirical measurements; (ii) that capillaries have a circular cross section, which in red-blooded species is $3.1 \mu \mathrm{m}$ in diameter (based on measurements from Notothenia coriiceps slow muscle) and in icefish is $4.5 \mu \mathrm{m}$ (based on measurements from Chaenocephalus aceratus slow muscle); (iii) that mitochondria consume oxygen at a rate of $4.0 \mathrm{ml} \mathrm{O}_{2} \mathrm{ml}^{-1} \mathrm{~min}^{-1}$ at $37^{\circ} \mathrm{C}$ and operate with a $\mathrm{Q}_{10}$ of 2.0; (iv) that capillaries are spaced at equidistant angles around the muscle fibre; (v) that mitochondria are not distributed homogeneously (the respective volume densities in the subsarcolemmal and intermyofibrillar zones are quantified separately); (vi) that, to accommodate data from different studies, lipid is distributed homogeneously throughout the fibre (see below); (vii) that Krogh's diffusion constant relative to water $(K r)$ is 5 for lipid $\left(K_{\mathrm{L}}\right)$ and 0.4 for cytoplasm $\left(K_{\mathrm{C}}\right)$ (a cytoplasmic value of $K_{\mathrm{C}}=0.5$ is assumed for icefish because of their lower protein concentration); (viii) that permeability is the weighted average of Krogh's diffusion constants for the lipid and cytoplasmic fraction, $p_{\mathrm{O}_{2}}=\left\{V \mathrm{v}\left(\right.\right.$ lip,f) $K_{\mathrm{L}}+\left[1-V \mathrm{v}(\right.$ lip,f) $\left.) K_{\mathrm{C}}\right\}=\left(D_{\mathrm{O}_{2}} \times S_{\mathrm{O}_{2}}\right)$, where $D_{\mathrm{O}_{2}}$ and $S_{\mathrm{O}_{2}}$ are oxygen diffusivity and solubility, respectively; (ix) that assumed myoglobin is zero or negligible in all species since myoglobin is not expressed in notothenioids and would, in any case, be ineffective at low temperatures; $(\mathrm{x})$ that mitochondrial cristae density and respiratory chain enzyme activity are similar among species, with the lower cristae density of icefish incorporated as a variant; and (xi) that blood flow is maximal and capillary $P_{\mathrm{O}_{2}}$ is $6 \mathrm{kPa}$.

The model allows the influence of the following variables to be examined: (i) Krogh's diffusion constant; (ii) fibre size; (iii) capillary size (iv) homogeneity of mitochondrial and lipid distribution and (v) interspecific differences when values are normalised for a common temperature.

\section{Statistical analyses}

The data were based on mean fibre composition, so statistical comparisons accounting for intraspecific variance were not possible, but we used a Student's $t$-test to indicate where significant interspecific differences were found on the basis of the mean \pm S.D. $P_{\mathrm{O}_{2}}$. 
Table 1. Oxygenation of pectoral skeletal muscle fibres in perciform fishes from different thermal environments

\begin{tabular}{|c|c|c|c|c|c|c|c|c|c|c|c|}
\hline Species & Region & Habitat & Activity & $\begin{array}{l}\text { Mass } \\
(\mathrm{g})\end{array}$ & $\begin{array}{l}\mathrm{SL} \\
(\mathrm{cm})\end{array}$ & $\begin{array}{c}\text { Temperature } \\
\left({ }^{\circ} \mathrm{C}\right)\end{array}$ & $\begin{array}{c}P_{\mathrm{O}_{2}} \\
(\mathrm{kPa})\end{array}$ & $\begin{array}{c}\text { Minimum } \\
P_{\mathrm{O}_{2}} \\
(\mathrm{kPa})\end{array}$ & $\begin{array}{c}\text { Fibre } \\
\text { area } \\
\left(\mu \mathrm{m}^{2}\right)\end{array}$ & $\mathrm{C}: \mathrm{F}$ & $\begin{array}{c}\begin{array}{c}V \mathrm{v} \\
(\mathrm{mit}, \mathrm{f})\end{array} \\
.\end{array}$ \\
\hline Trematomus newnesi & Ant & Pelagic & Active & $17 \pm 4$ & $11 \pm 0.5$ & 0 & $5.796 \pm 0.099$ & 5.619 & 238 & 1.3 & 0.31 \\
\hline Lepidonotothen nudifrons & Ant & $\begin{array}{l}\text { Demersal/ } \\
\text { pelagic }\end{array}$ & Moderate & $35 \pm 6$ & $8+4$ & 0 & .531 & 3.676 & 1052 & .2 & 0.29 \\
\hline Notothenia & Ant & Demersal & 然 & $698 \pm 82$ & $32 \pm 2$ & 0 & 3290 & 2.303 & 1638 & 1.2 & 0.27 \\
\hline Chaenoc & Ant & Demersal & Sluggish & $1191 \pm 94$ & $49 \pm 1$ & 0 & $1.190=$ & 0 & 2932 & 1.5 & 0.53 \\
\hline Paranotothenia magellanica & Sub & Pelagic & Active & $65 \pm 10$ & $16 \pm 1$ & 4 & $5.815 \pm 0.073$ & 5683 & 289 & 2.0 & 0.27 \\
\hline El & & & & & & & & & & .1 & 0.33 \\
\hline essellata & Sub & Demersal & Sluggish & $116 \pm 22$ & $18 \pm$ & & 64 & 3.5 & 1345 & 3.0 & 0.33 \\
\hline Champsocephalus esox & Sub & Pelagic & Active & $82 \pm 8$ & $24 \pm 1$ & 4 & $1.970 \pm 1.330$ & 0.668 & 2427 & 3.0 & 0.51 \\
\hline Paranotothenia magellanica & Sub & & & & & 10 & & & 289 & 2.0 & 0.27 \\
\hline & & & & & & & & & & 3.1 & 0.33 \\
\hline llata & Sub & Deme & Sluogi & $116=$ & $18 \pm$ & 1( & & 2.265 & 1345 & 3.0 & 0.33 \\
\hline Champsocephalus esox & Sub & Pelagic & Active & $82 \pm 8$ & $24 \pm 1$ & 10 & $0.719 \pm 1.511$ & 0 & 2427 & 3.0 & 0.51 \\
\hline ormyrus & Ied & $\mathrm{Pe}$ & Moder: & $57 \pm 5$ & $14 \pm$ & 20 & 122 & 5.425 & 327 & 3.5 & 0.13 \\
\hline Coris julius & Med & Pelagic & Active & $12 \pm 4$ & $10 \pm 1$ & 20 & $5.052 \pm 0.383$ & 5.437 & 408 & 2.8 & 0.32 \\
\hline
\end{tabular}

Ant, Antarctic; Sub, sub-Antarctic; Med, Mediterranean; C:F, capillary-to-fibre ratio; $V v($ mit,f), mitochondrial volume density; SL, standard length.

Mean values \pm S.D. are for a distribution of values based on mean structural data ( $N=961$ grid points).

\section{Results}

The structural variables used as input to the oxygen diffusion model are shown in Table 1. Differences in fibre dimensions are largely a function of the mean body mass of the fish studied. The slow fibres studied were isolated from the reddest area of the pectoral fin adductor muscle (see Fernandez et al., 2000). The data on mitochondrial volume density were taken from Johnston et al. (1998) and S. Egginton and C. Skilbeck (unpublished results), whereas the measurements of the capillary bed are from the present study.

\section{Antarctic species}

The volume density of mitochondria, $V v(m i t, f)$, in the three red-blooded notothenioids was in the range $0.27-0.31$ (Table 1). The mean muscle fibre cross-sectional area was 6.9 times higher in Notothenia coriiceps than in Trematomus newnesi, largely reflecting their relative body masses (Table 1). The capillary-to-fibre ratio was, however, similar (1.2-1.3) in all three species (Table 1). Plots of the modelled intracellular oxygen tension against muscle fibre radius for these species are shown in Fig. 1A-C. There was no reduction in $P_{\mathrm{O}_{2}}$ across the relatively narrow slow fibres of Trematomus newnesi (Fig. 1A), and a small (16\%) reduction across fibres in Lepidonotothen nudifrons, which had approximately twice the mean radius (Fig. 1B). The relationship between fibre radius and the calculated intracellular $P_{\mathrm{O}_{2}}$ was complex. For example, although the fibre radius in Notothenia coriiceps was only $23 \%$ greater than in Lepidonotothen nudifrons, the reduction in oxygen tension at the centre of the fibres was substantially (30\%) greater (Fig. 1B,C). The mean slow fibre radius in Chaenocephalus aceratus was 3.5 times that of
Trematomus newnesi and, whereas $V \mathrm{v}(\mathrm{mit}, \mathrm{f})$ was substantially higher $\left(51 \%\right.$ ) (Table 1), calculated $P_{\mathrm{O}_{2}}$ was more than $99 \%$ lower in the centre of the fibre (Fig. 1D).

\section{Sub-Antarctic species}

The sub-Antarctic notothenioids had a similar $V \mathrm{v}(\mathrm{mit}, \mathrm{f})$ to the high-latitude confamilial species (range 0.27-0.33) (Table 1). However, there were approximately twice as many capillaries per fibre (C:F 2.0-3.1) (Table 1). Model simulations predicted that the two species with the narrowest fibres, Paranotothenia magellanica (Fig. 2A) and Eleginops maclovinus (Fig. 2B), would have a negligible drop in oxygen tension across the fibre at the average winter $\left(4^{\circ} \mathrm{C}\right)$ temperature. The $P_{\mathrm{O}_{2}}$ drop in Patagonotothen tessellata (Fig. 2C) was similar to that observed in the Antarctic species Lepidonotothen nudifrons but half that in Notothenia coriiceps, both of which had slow fibres with a similar mean diameter (Fig. 1B,C). At the summer temperature of $10^{\circ} \mathrm{C}$, mean $P_{\mathrm{O}_{2}}$ was only approximately $2 \%$ lower than that in winter for Paranotothenia magellanica and Eleginops maclovinus (Fig. 2E,F), whereas in Patagonotothen tessellata (Fig. 2G) the decrease was 10 times greater $(21 \%)$. Slow fibres in the sub-Antarctic icefish Champsocephalus esox had a similar mitochondrial volume density to those in the Antarctic icefish (0.51) but a twofold higher capillary-to-fibre ratio (Table 1). In summer, the predicted intracellular oxygen tension was $50 \%$ lower than in winter (Fig. 2D,H), being similar to that of the Antarctic channichthyid Chaenocephalus aceratus (Table 1).

\section{Mediterranean species}

In the warmer, low-latitude perciform species, there was a 
Fig. 1. (A-D). Wire frame plots of calculated intracellular $P_{\mathrm{O}_{2}}$ $(\mathrm{kPa})$ in slow oxidative fibres of the locomotory (pectoral) muscles from Antarctic notothenioid species. $P_{\mathrm{O}_{2}}$ is on the vertical axis and fibre radius $(\mu \mathrm{m})$ on the horizontal axes, with the centre at $(0,0)$. The highest $P_{\mathrm{O}_{2}}$ value $(6 \mathrm{kPa})$ represents that of capillaries around a fibre; this declines both radially and circumferentially, initially with a steep gradient that quickly levels out towards the inner part of the fibre. The integrated response of differences in fibre size and intracellular compartments is predicted to maintain a similar level of tissue oxygenation at a cell temperature of $0^{\circ} \mathrm{C}$ when fibre radius is small. When fibre girth is increased, the decrease in mean $P_{\mathrm{O}_{2}}$ is pronounced, an effect that is accentuated within the fibres of the channichthyid Chaenocephalus aceratus, where anoxic regions are predicted to occur. See text for details.

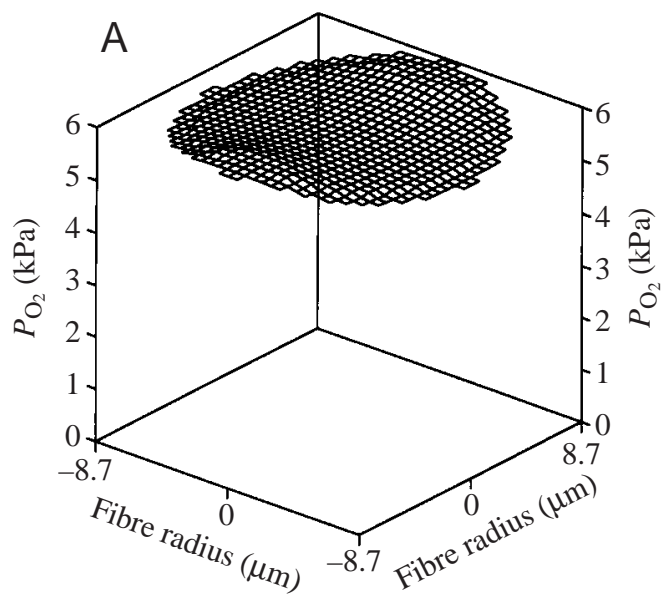

Trematomus newnesi

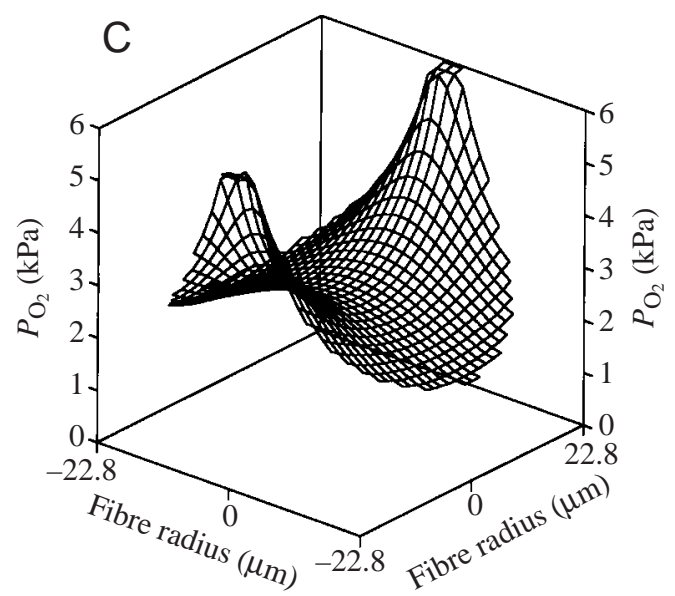

Notothenia coriiceps

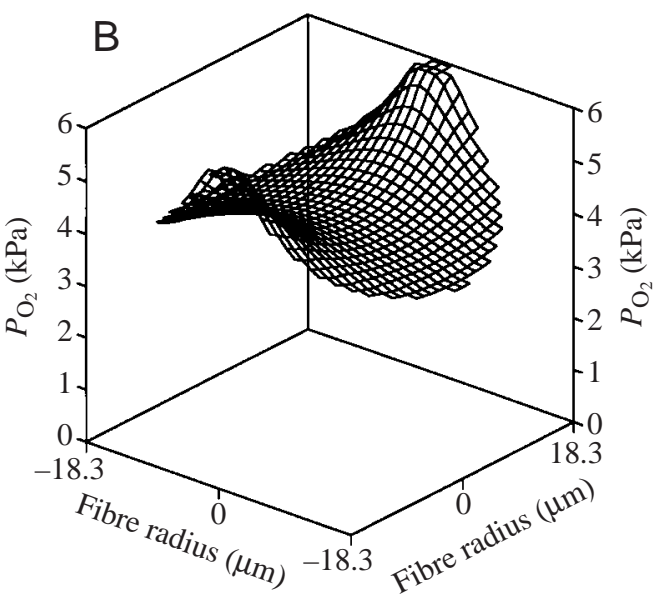

Lepidonotothon nudifrons

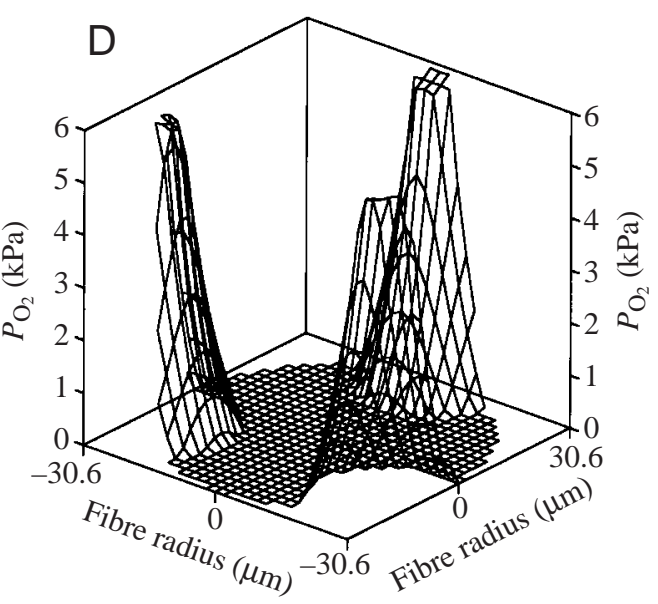

Chaenocephalus aceratus
$60 \%$ difference in $V \mathrm{v}$ (mit,f) (Table 1). However, as the fibre radius was small and capillary supply moderate to high, the muscle fibres are predicted to have an intracellular $P_{\mathrm{O}_{2}}$ in excess of $5 \mathrm{kPa}$ (Fig. 3), similar to that seen in Trematomus newnesi from the Antarctic at $0{ }^{\circ} \mathrm{C}$.

\section{Determinants of fibre $\mathrm{P}_{O_{2}}$}

Krogh's diffusion constant $(K r$, the arithmetic product of the diffusion coefficient for oxygen, $D_{\mathrm{O}_{2}}$, and the solubility constant for oxygen, $\mathrm{S}_{\mathrm{O}_{2}}$ ) is conveniently expressed relative to that of water, and a value of $K r=0.4$ is appropriate for a nominal cell protein concentration of $30 \mathrm{mg} \mathrm{m}^{-1}$. However, lower values for trunk muscle protein concentration may increase $K r$ to 0.5 or above and, hence, lead to a potentially higher mean $P_{\mathrm{O}_{2}}$ than that predicted using the standard input variables (Fig. 4A). Most vertebrates have a capillary diameter of approximately $2.1 \mu \mathrm{m}$, although nototheniid vessels are somewhat larger, at $3.1 \mu \mathrm{m}$, and those from channichthyids are even larger, at $4.5 \mu \mathrm{m}$. There is an increase in oxygen tension across this range of vessel size as the larger vessel circumference allows for an increased outflow of oxygen (Fig. 4B). Fibre size has a major influence on calculated intracellular oxygen tension (Fig. 4C). Indeed, mean $P_{\mathrm{O}_{2}}$ varies directly with fibre cross-sectional area, irrespective of species or geographical zone/environmental temperature at which the notothenioids live (Fig. 5A). Thus, there is little inter-specific difference in mean $P_{\mathrm{O}_{2}}$ when the variation in $V \mathrm{v}$ (mit,f) among species is normalised by calculating the total mitochondrial volume per unit fibre length (Fig. 5B). The complementary changes due to these major influences are illustrated for Chaenocephalus aceratus by iteratively varying fibre radius at the normal environmental temperature (Fig. 6B) and environmental temperature at normal fibre radius (Fig. 6A).

\section{Discussion}

The Antarctic fish fauna present a rare opportunity to examine the response of ectothermic vertebrates to an essentially unchanging, very cold environment. In addition, the unique endemic speciation within the marine environment allows closely related species of differing ecotypes and morphologies to be compared. However, as a consequence of low species diversity and predation pressure, these fishes may not need to conform as fully to the environment compared with 


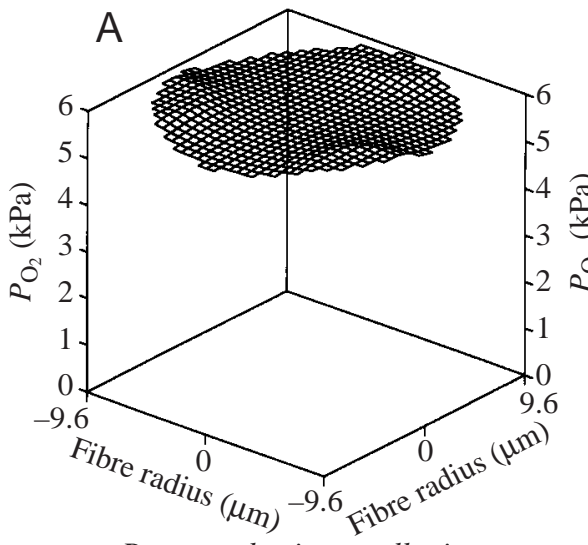

Paranotothenia magellanica

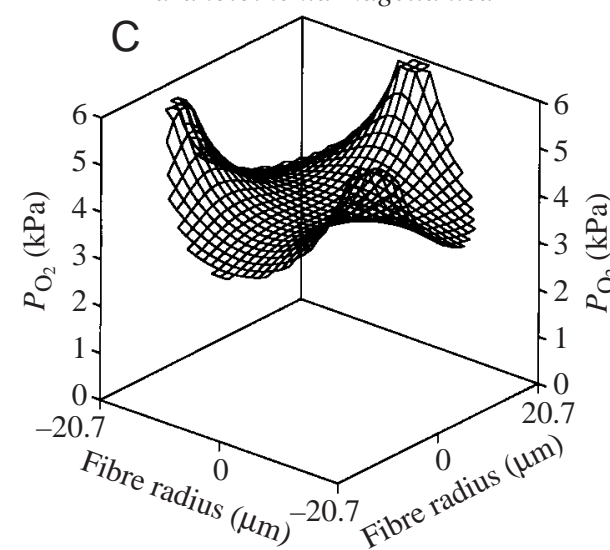

Patagonotothen tessellata

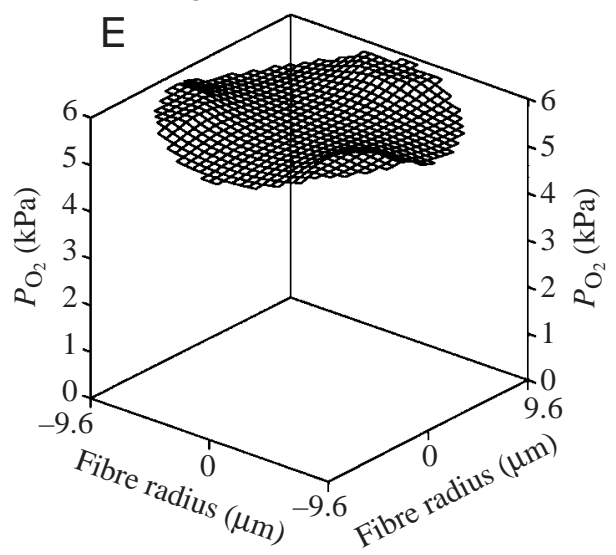

Paranotothenia magellanica

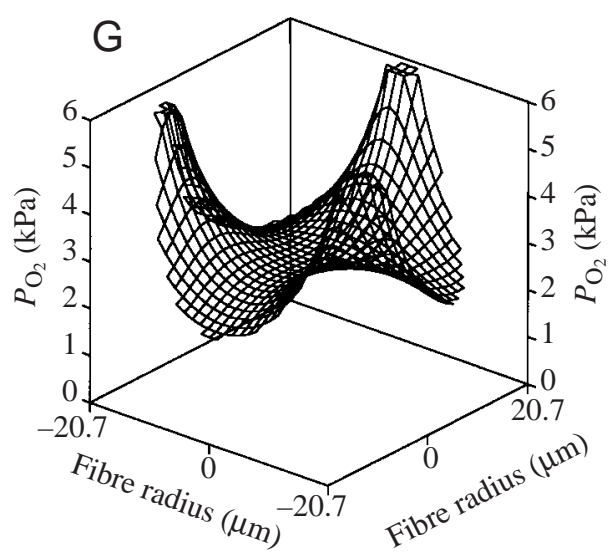

Patagonotothen tessellata

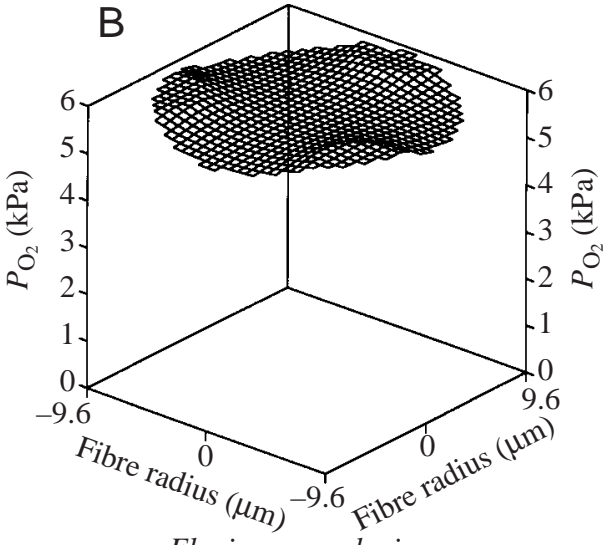

Eleginops maclovinus

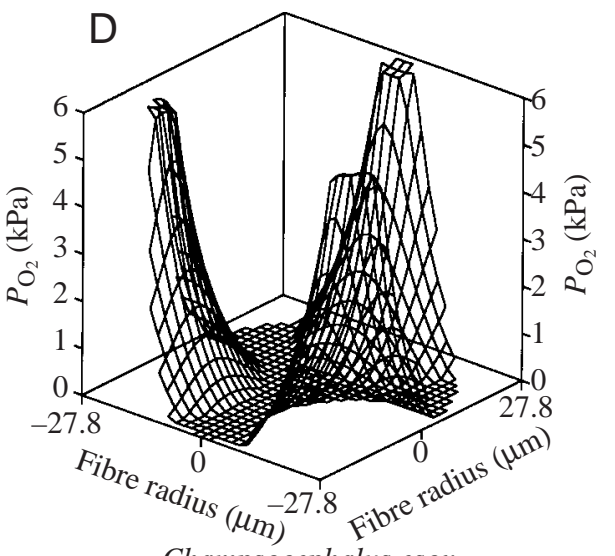

Champsocephalus esox

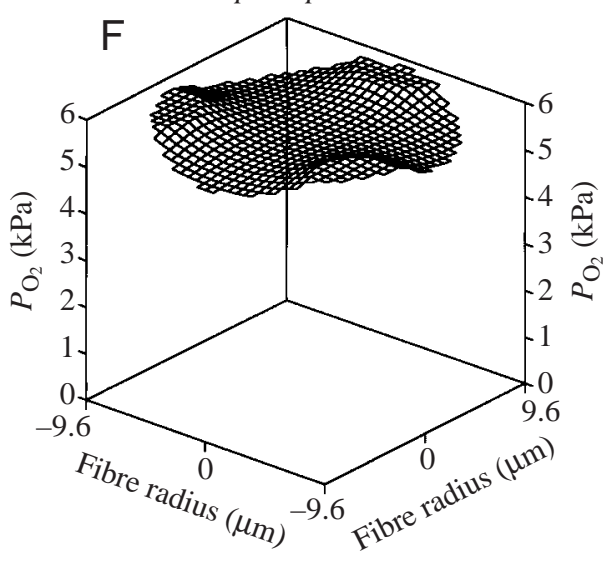

Eleginops maclovinus

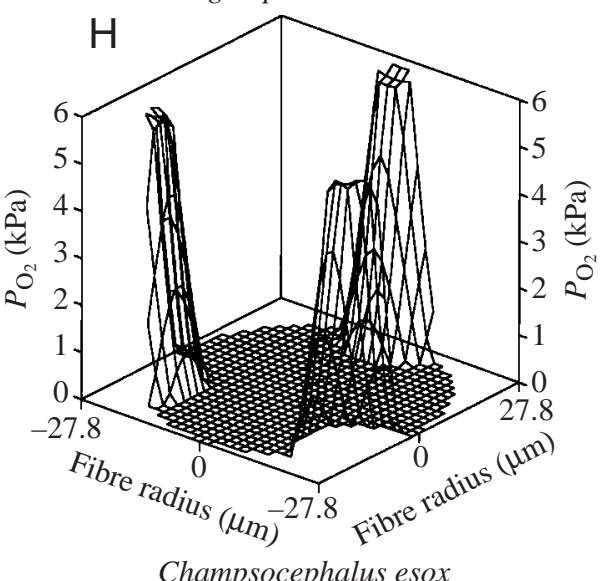

Fig. 2. Intracellular $P_{\mathrm{O}_{2}}(\mathrm{kPa})$ in slow pectoral muscle fibres of notothenioids from the sub-Antarctic region. The integrated response of differences in fibre radius and intracellular compartments is predicted to maintain a similar level of tissue oxygenation at cell temperatures experienced during winter (A-D) and summer $(\mathrm{E}-\mathrm{H})\left(4\right.$ and $10^{\circ} \mathrm{C}$, respectively). The icefish Champsocephalus esox shows a potential hypoxaemia that is particularly evident at the higher temperature $(\mathrm{H})$.

other ecosystems and, hence, challenge the usual concept of all species evolving to the same adaptionist pinnacle. In addition, the relatively short period of stock isolation may mean that the present fauna present an incomplete process of cold adaptation. Indeed, it is clear from the Channichthyidae that cardiovascular adaptations do not compensate fully for the loss of respiratory pigments. We used a mathematical model of peripheral oxygen supply to explore the major influences on oxygen delivery to locomotory muscle, accepting that our current understanding of the physiology is incomplete and that a perfect model does not exist.

\section{Temperature}

Bearing in mind these limitations, model iterations are helpful to illustrate the physiological limits likely to be imposed by current phenotype, and also to gauge the effect of any change in environmental temperature as a result of climatic change or altered distribution patterns. For example, should Chaenocephalus aceratus be faced with the annual range of temperatures experienced by Champsocephalus esox, we calculate a mean fibre $P_{\mathrm{O}_{2}}$ of $\quad 0.89 \pm 1.51 \mathrm{kPa}$ at $\quad 4^{\circ} \mathrm{C}$ and $0.45 \pm 1.31 \mathrm{kPa}$ at $10^{\circ} \mathrm{C}$ (means \pm S.D.), with a significant proportion of mitochondria along the fibre radius experiencing anoxia. Clearly, these animals are well-adapted to the extreme stenothermal environment of the Southern Ocean, but structurally would appear to be ill-equipped to 
Fig. 3. Calculated intracellular $P_{\mathrm{O}_{2}}$ $(\mathrm{kPa})$ in slow pectoral muscle fibres of Mediterranean perciform fishes. The integrated response of differences in fibre radius and intracellular compartments is predicted to maintain an unvarying high level of tissue oxygenation at a cell temperature of $20^{\circ} \mathrm{C}$.

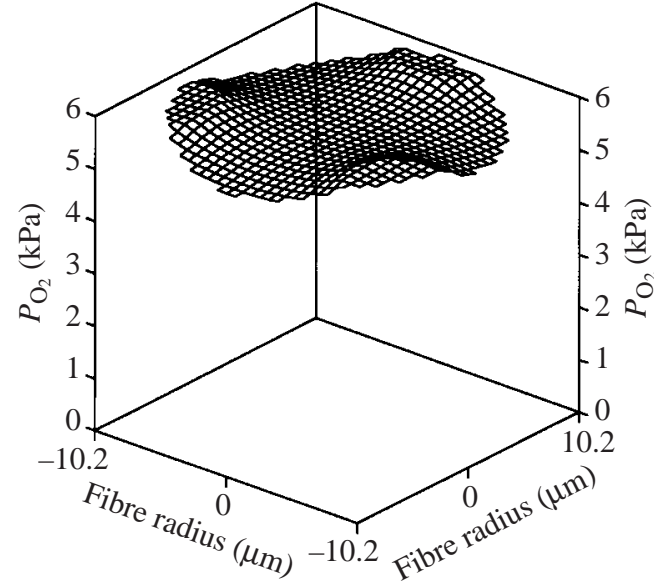

Lithognathus mormyrus

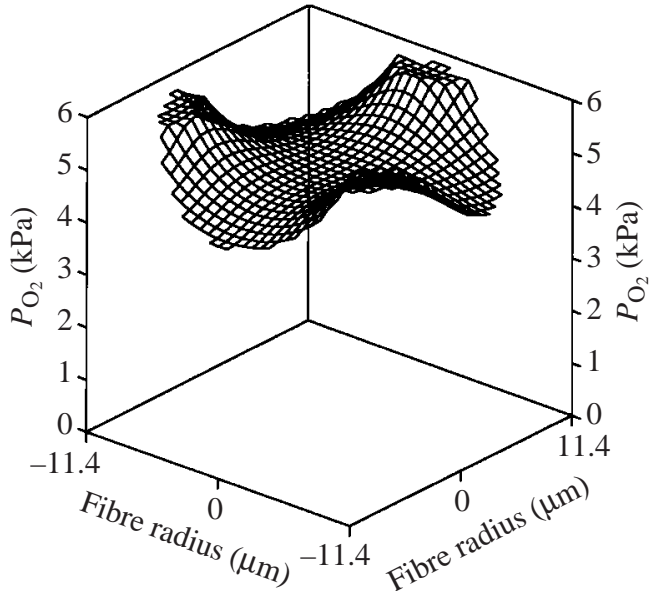

Coris julius cope with any perturbation in temperature, indicating a loss of plasticity. The environmental temperature in the Beagle Channel ranges from $4{ }^{\circ} \mathrm{C}$ in winter to a maximum of $10-11^{\circ} \mathrm{C}$ in summer. This may be extended by several degrees in both directions in shallow bay waters, and the intertidal nesting species Patagonotothen tessellata and Harpagifer bispinnis survive extreme diurnal temperature ranges during summer spawning and in persistent cold water while guarding their nests during nocturnal low tides in July and August.

There is evidence for a possible adaptation in peripheral oxygen transport among the Channichthyes, with Champsocephalus esox calculated to exhibit a mean intracellular $P_{\mathrm{O}_{2}}$ of $1.43 \pm 1.51 \mathrm{kPa}(K r=0.4)$ or $2.36 \pm 1.20 \mathrm{kPa} \quad(K r=0.5)$ (means \pm S.D.) at $0^{\circ} \mathrm{C}$, far higher than that predicted for Chaenocephalus aceratus at $0{ }^{\circ} \mathrm{C}$. Aerobic muscle performance is likely also to be aided by the presence of ventricular myoglobin in some channicthyid species (Acierno et al., 1997). In Champsocephalus esox, the ventricular muscle has an orangepink appearance (J. Calvo, personal observation) that may indicate the presence of myoglobin in this species as well, which would help preserve cardiac output under conditions of metabolic stress, although it may simply reflect cytochrome colour. One captive specimen of Champsocephalus esox survived $6 \mathrm{~h}$ of exposure to $14^{\circ} \mathrm{C}$ while maintaining the ability to swim (J. Calvo, personal observation) at this temperature, where intracellular $P_{\mathrm{O}_{2}}$ is calculated to average $0.47 \mathrm{kPa}$, with regions of anoxia. In contrast to the channichthyids, the red-blooded Antarctic notothenioids, including the sluggish Notothenia coriiceps, are predicted to show a marked resilience to elevated temperature and, with care, may be gradually acclimated in the laboratory to temperatures experienced by their sub-Antarctic cousins (S. Egginton, unpublished data). For example, Lepidonotothen nudifrons would be predicted to decrease mean intracellular $P_{\mathrm{O}_{2}}$ by $75 \%$ when raised from 0 to $20^{\circ} \mathrm{C}$, whereas Trematomus newnesi would only have a modest $8 \%$ reduction because of its smaller fibre size (Table 2 ).

\section{Fibre cross-sectional area}

As suggested by the model, fibre radius, representing the distance over which intracellular diffusion must take place, has a major influence on calculated intracellular oxygen tension. From the Krogh model, the relationship between $\mathrm{P}_{\mathrm{O}_{2}}$ and fibre cross-sectional area is much more linear than that between $P_{\mathrm{O}_{2}}$ and fibre radius; a fivefold increase in area is equivalent to a $124 \%$ increase in radius. Using the appropriate capillary radius and $K r$ value, the very large radius of slow fibres in channichthyid muscle probably represents an upper limit to adequate oxygenation; if the fibre size were similar to that found in nototheniids, there would be a substantial increase in calculated $P_{\mathrm{O}_{2}}$ (to $3.13 \pm 0.99 \mathrm{kPa}$ ). Indeed, mean $P_{\mathrm{O}_{2}}$ varies directly with fibre size, such that a change in fibre area of $50 \%$ would lead to an approximately fourfold difference in calculated oxygen tension. Fibre size normally varies directly with body size. Most of the fish studied were relatively small specimens, e.g. in Patagonotothen tessellata, the maximum diameter of slow fibres was approximately $100 \mu \mathrm{m}$, whereas fast fibres reach a diameter of $600 \mu \mathrm{m}$, while the icefishes were relatively large compared with the other species examined.

Table 2. Projected oxygenation of pectoral skeletal muscle fibres with homogeneous composition in Antarctic nototheniids at different temperatures

\begin{tabular}{lccc}
\hline Species & $\begin{array}{c}\text { Temperature } \\
\left({ }^{\circ} \mathrm{C}\right)\end{array}$ & $\begin{array}{c}P_{\mathrm{O}_{2}} \\
(\mathrm{kPa})\end{array}$ & $\begin{array}{c}\text { Minimum } \\
P_{\mathrm{O}_{2}} \\
(\mathrm{kPa})\end{array}$ \\
\hline Trematomus newnesi & 0 & $5.78 \pm 0.10$ & 5.63 \\
Lepidonotothen nudifrons & 0 & $4.30 \pm 0.54$ & 3.60 \\
T. newnesi & 4 & $5.75 \pm 0.11$ & 5.59 \\
L. nudifrons & 4 & $4.11 \pm 0.60$ & 3.35 \\
T. newnesi & 10 & $5.63 \pm 0.16$ & 5.38 \\
L. nudifrons & 10 & $3.15 \pm 0.91$ & 1.98 \\
T. newnesi & 20 & $5.32 \pm 0.29$ & 4.86 \\
L. nudifrons & 20 & $1.03 \pm 1.47$ & 0
\end{tabular}

Input variables: fibre radius, $22.8 \mu \mathrm{m}$; capillary radius, $3.1 \mu \mathrm{m}$; Krogh's diffusion coefficient $(k r)=0.4$; mitochondrial volume density, $V \mathrm{v}($ mit,f) and capillary-to-fibre ratio, $\mathrm{C}: \mathrm{F}$, as in Table 1.

Values are means \pm S.D. ( $N=961$ grid points). 

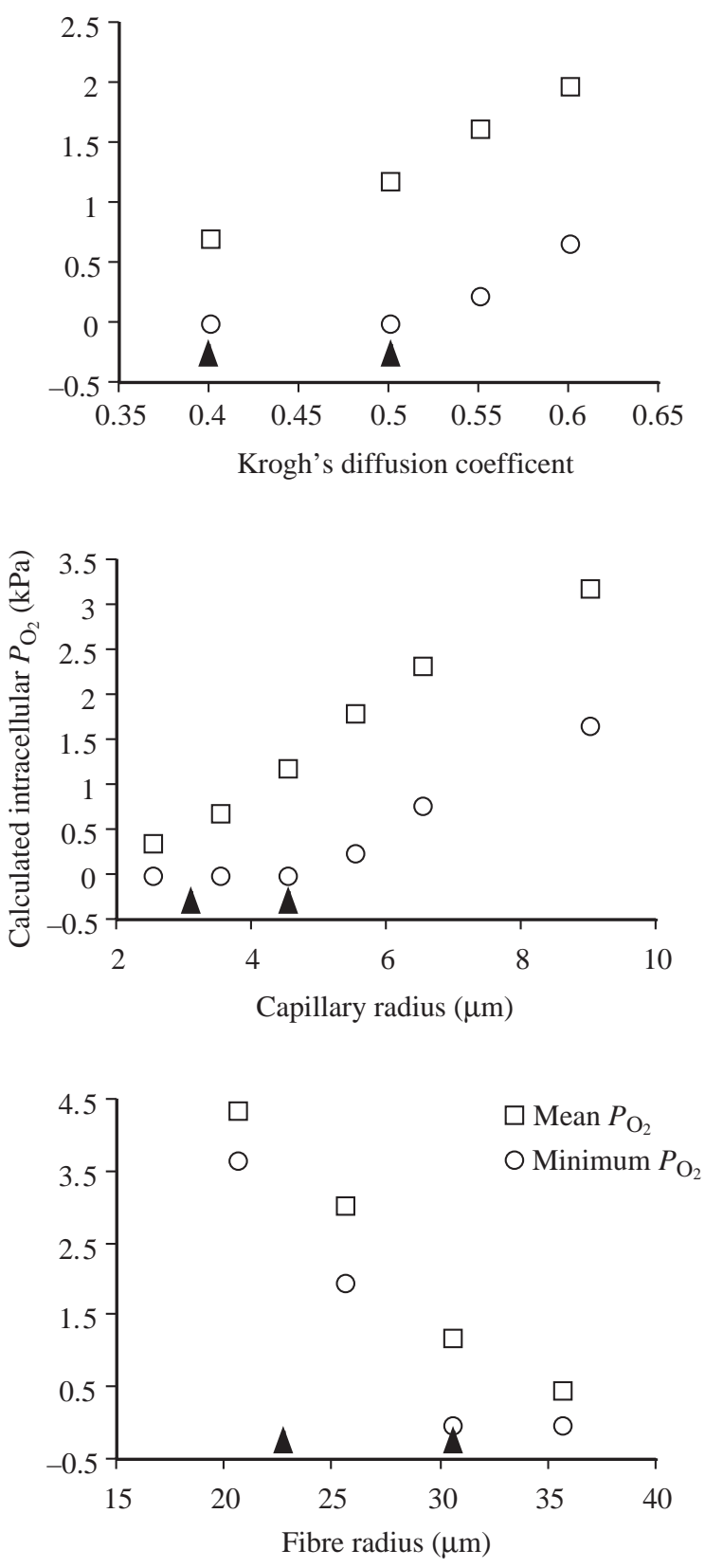

Fig. 4. (A) Influence of Krogh's diffusion coefficient on the calculated mean (squares) and minimum (circles) fibre $P_{\mathrm{O}_{2}}$. Arrowheads point to the values derived for nototheniid (left) and channichthyid (right) muscle protein concentrations. (B) Influence of capillary radius on intracellular oxygen tension. Right arrowhead, icefish vessels; left arrowhead, nototheniid vessels. (C) Influence of fibre radius on oxygenation. Right arrowhead, icefish fibres; left arrowhead, nototheniid fibres.

Large fibre diameter is a function of notothenioid fishes in general, rather than of icefishes, and many of the differences observed may be a function of body size. This relationship between fibre cross-sectional area and mean $P_{\mathrm{O}_{2}}$ was found irrespective of species or geographical zone/environmental temperature at which the notothenioids live and is maintained if the variation in $V v($ mit,f) among species is normalised by
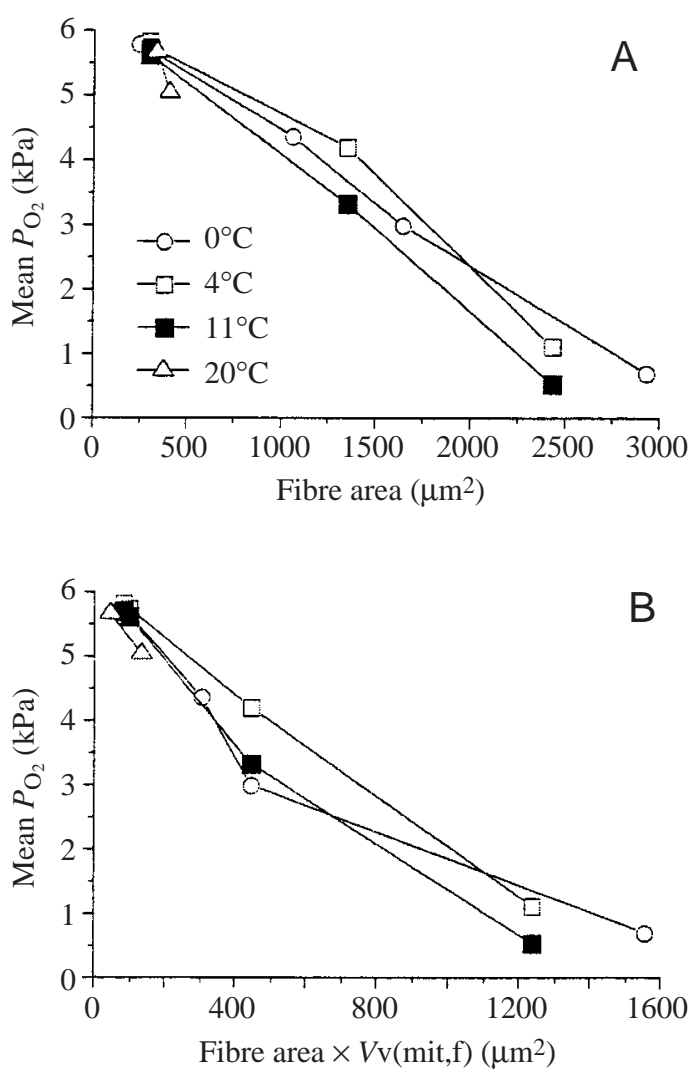

Fig. 5. (A) The relationship between calculated mean fibre $P_{\mathrm{O}_{2}}$ and fibre cross-sectional area $\left(\mu \mathrm{m}^{2}\right)$ for notothenioids living at $0-20{ }^{\circ} \mathrm{C}$; the overall regression (not plotted) is $P_{\mathrm{O}_{2}}=6.31-0.002$ (fibre area) $\left(r^{2}=0.97\right)$. (B) The relationship between calculated mean fibre $P_{\mathrm{O}_{2}}$ and total mitochondrial volume per unit length of fibre, $V($ mit,f), is $V($ mit, $\mathrm{f})=V \mathrm{v}($ mit, $\mathrm{f})($ fibre area $)$, where $V($ mit,f) is mitochondrial volume density, for notothenioids living at $0-20^{\circ} \mathrm{C}$; the overall regression (not plotted) is $P_{\mathrm{O}_{2}}=5.74-0.004 \mathrm{~V}$ (mit,f) $\left(r^{2}=0.94\right)$.

calculating the total mitochondrial volume per unit fibre length (Fig. 5).

Increasing fibre girth may be a secondary effect of the differences in habitat temperature during development as a result of the protracted larval stage of the Antarctic species, which can be extended over most of the winter, spring and summer months (Kock, 1992). The majority of Antarctic and sub-Antarctic notothenioids show an unusual pattern of muscle growth characterised by limited fibre recruitment, resulting in slow and fast fibre diameters in excess of 60 and $550 \mu \mathrm{m}$, respectively (Fernandez et al., 2000). However, it is likely that the presence of large-diameter fibres has a phylogenetic explanation and simply reflects a limitation on fibre recruitment in these species rather than some specific adaptation to life in cold waters (I. A. Johnston, unpublished results). There is taxonomic variation in fibre number, with Eleginops maclovinus only having one-fifth of the number of fibres of a salmon of the same body size but 10 times more fibres than other species in the family Notothenidae that can reach the same body size (I. A. Johnston, unpublished observations). It may be that low temperature is 

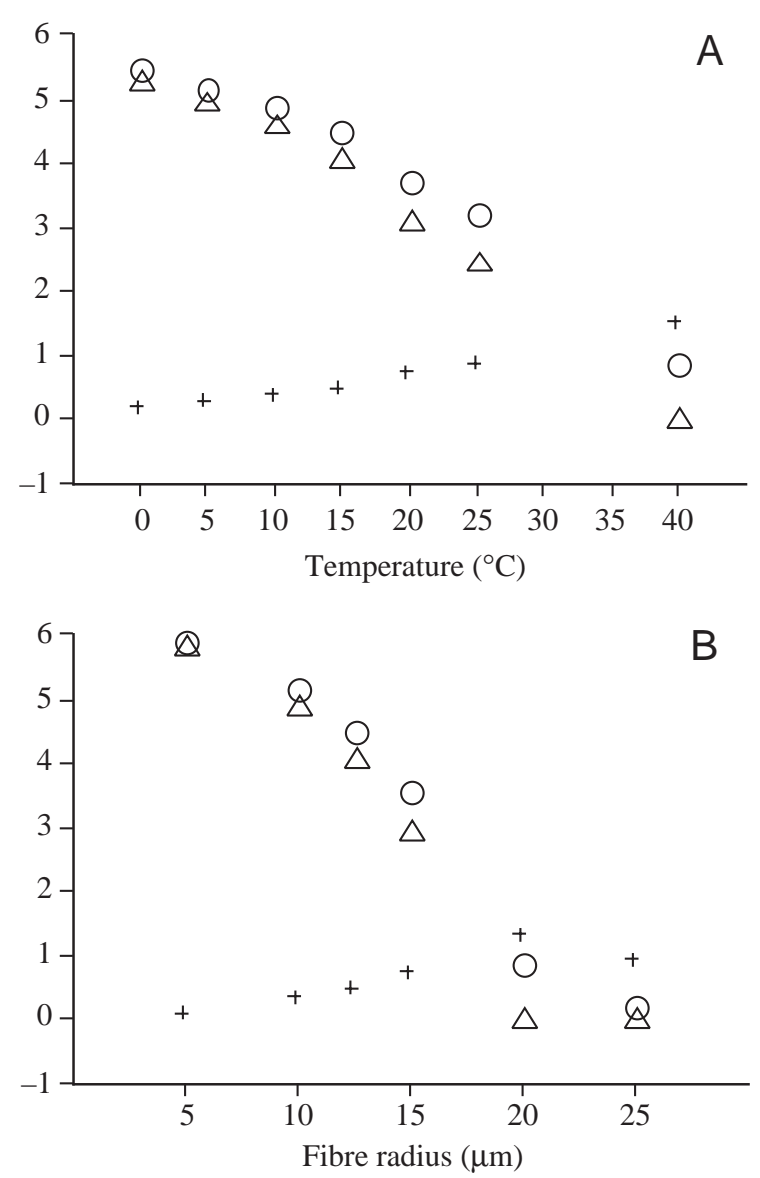

Fig. 6. The relative influence of cell temperature (A) and fibre radius (B) on calculated oxygen tensions in Chaenocephalus aceratus. Circles, mean fibre $P_{\mathrm{O}_{2}}$; plus signs, $P_{\mathrm{O}_{2}}$ standard deviation; triangles, minimum fibre $P_{\mathrm{O}_{2}}$. Input variables were as follows: fibre radius 12.5 $\mu \mathrm{m}(\mathrm{A})$, temperature $15^{\circ} \mathrm{C}(\mathrm{B})$; common variables were Krogh's diffusion coefficient (0.4), the number of capillaries (2), mitochondrial volume density $(0.2)$ and capillary radius $(2.1 \mu \mathrm{m})$.

permissive for large-diameter fibres, i.e. having large fibres may not be a disadvantage and it may help to reduce resting metabolic rate. This may explain the apparent paradox of large fibres under conditions of low diffusivity, suggesting that selection pressure during notothenioid radiation was not primarily directed at maintaining a high intracellular oxygen tension. Nevertheless, this wide range of fibre size is likely to have a direct effect on mean fibre $P_{\mathrm{O}_{2}}$. At the extreme of large fibres (icefish), calculated $P_{\mathrm{O}_{2}}$ was zero at the fibre centre (Fig. 1). This may seem odd because mitochondria are distributed right to the centre of the fibres in this species (Archer and Johnston, 1991); however, this simply means that mitochondria can respire at sub-maximal $\dot{M}_{\mathrm{O}_{2}}$ and that a proportion would be non-functional at $\dot{M}_{\mathrm{O}_{2} \max }$, thus limiting aerobic power output.

\section{Mitochondrial content}

In most vertebrates, the mitochondrial structure and massspecific rate of oxygen consumption appear to be relatively invariant, such that mitochondrial volume varies directly with $\dot{M}_{\mathrm{O}_{2}}$ (Hoppeler et al., 1987). The model uses a standard value for mitochondrial respiration of $4.0 \mathrm{ml} \mathrm{O}_{2} \mathrm{ml}^{-1} \mathrm{~min}^{-1}$, based on studies of whole-muscle $\dot{M}_{\mathrm{O}_{2}}$ at the $\dot{M}_{\mathrm{O}_{2} \text { max }}$ for individual species (Hoppeler et al., 1987), scaled for the effect of temperature $\left(\mathrm{Q}_{10}=2\right)$. Although a number of studies have suggested there is little effect of acclimation or environmental temperature on mitochondrial structure (Egginton and Sidell, 1989; Johnston et al., 1994), and hence mass-specific $\dot{M}_{\mathrm{O}_{2}}$, recent data suggest that some notothenioids may have an unusually low respiratory capacity (Johnston et al., 1998). In this case, the high value for $\operatorname{Vv}(\mathrm{mit}, \mathrm{f})$ may be an inadequate index of fibre oxidative capacity, although whether this is a result of lower cristae density or is compounded by an altered respiratory chain density is unclear.

However, using the $30 \%$ lower cristae surface density reported by Archer and Johnston (1991) to rescale the $\dot{M}_{\mathrm{O}_{2}}$ in the model makes little qualitative difference to our conclusions because it would result in a twofold higher calculated mean $P_{\mathrm{O}_{2}}$ in m. pectoralis, e.g. increasing it to $2.62 \pm 1.06 \mathrm{kPa}$ (mean \pm S.D.) for the channichthyid at $0{ }^{\circ} \mathrm{C}$. Even if cristae density were $60 \%$ lower than that of nototheniids assumed in these calculations, the mean $P_{\mathrm{O}_{2}}$ of Chaenocephalus aceratus would still only be the same as that of Notothenia coriiceps $(3.10 \pm 0.91 \mathrm{kPa})$ (mean \pm S.D.) and markedly less than that of the red-blooded notothenioids, which have small diameter fibres. However, it would take a rather modest reduction in $\dot{M}_{\mathrm{O}_{2}}$ of only approximately $10 \%$ to raise the minimum oxygen tension towards that adequate for unimpeded mitochondrial respiration $(0.3 \mathrm{kPa})$, a likely consequence of a relatively low specific activity of citrate synthase in these animals (S. Egginton, S. Skilbeck and S. Cordiner, in preparation).

\section{Diffusion constant}

We have compiled data on the fine structure of slow muscle fibres from the locomotory muscle of perciform species inhabiting a wide range of environmental temperatures and examined the consequences for intracellular oxygen delivery. While the major determinants of tissue oxygen tension are the capillary supply and intracellular diffusion distance, other factors such as the composition of the cytosol may play a modifying role in the diffusivity of oxygen (Hoofd and Egginton, 1997). For example, the value for Krogh's diffusion constant relative to water normally used is based on a nominal cell protein concentration of $30 \mathrm{mg} \mathrm{ml}^{-1}$, whereas we have found significantly lower values for trunk muscle protein concentration in channichthyids (N. M. Whiteley and S. Egginton, unpublished data). It is calculated that, in pectoral muscle fibres of Chaenocephalus aceratus, this difference may significantly increase $\mathrm{Kr}$ and hence lead to a potentially higher mean $P_{\mathrm{O}_{2}}$ than that predicted using the standard input variables. Although the value of $K r=0.5$ used in the present study may be conservative, for the minimum $P_{\mathrm{O}_{2}}$ to be increased above zero would require a more watery muscle than is actually found. 


\section{Fibre composition}

Changes in fibre composition that occur during cold acclimation which may affect the intracellular flux of oxygen include increased lipid and mitochondrial content (Egginton and Sidell, 1989). Because oxygen solubility is higher in lipid than in aqueous solution, and the diffusion coefficient for oxygen was unaltered by acclimation, the calculated diffusion constant is greater in cold- than in warm-acclimated fish (Desaulniers et al., 1996; Hoofd and Egginton, 1997). However, in the notothenioid species we examined, the lipid content was relatively low, suggesting that other structural parameters may play a limiting role. The influence of mitochondrial content has been discussed previously. In addition, as the model uses assumptions designed to examine the capacity for oxygen transport to tissue, any deviations from optimal conditions will clearly reduce the apparent efficiency of the process. For example, the model assumes a homogeneous cytoplasmic composition in each domain, whereas in reality both capillary supply and mitochondrial distribution are often quite heterogeneous in vivo, leading to some impairment of supply on the basis of simple diffusion. This is particularly the case for the distribution of intracellular membranes, and the permeability to oxygen is therefore likely to be particularly heterogeneous.

Membranes are unlikely to be oxygen barriers, but may restrict the intracellular distribution of myoglobin and lipid. However, any reticulum of lipid-rich structures such as the sarcoplasmic reticulum or ribbons of mitochondria may act as low-resistance conduits for intracellular flux of oxygen (Longmuir, 1980). Although the model is unable to incorporate such structural heterogeneity, we can estimate the likely influence that different cellular organisation may have. For example, values for intracellular $\mathrm{P}_{\mathrm{O}_{2}}$ in Notothenia coriiceps based on normalised data (Table 3 ) but at $0{ }^{\circ} \mathrm{C}$ were $3.29 \pm 0.79$ and $2.30 \mathrm{kPa}$ (mean \pm S.D. and minimum), which would be reduced to $3.21 \pm 0.80$ and $2.42 \mathrm{kPa}$, respectively, if the mitochondria were homogeneously distributed between the subsarcolemmal and intermyofibrillar zones across the fibre, to $3.20 \pm 0.80$ and $2.20 \mathrm{kPa}$ for homogeneous lipid distribution and to $3.12 \pm 0.81$ and $2.33 \mathrm{kPa}$ if both components were homogeneously distributed between the subsarcolemmal and intermyofibrillar zones. The other species were predicted to be affected to a similar degree if these organelles were not distributed in a heterogeneous manner.

\section{Capillary radius}

The influence of capillary radius is not usually considered in modelling studies as most vertebrates have a similar vessel bore through which erythrocytes have to deform during tissue perfusion. Our studies have shown, however, that nototheniid vessels are somewhat larger than the norm for vertebrates, while those from channichthyids are considerably larger still. The large bore of icefish vessels has previously been discussed exclusively in terms of its influence on blood
Table 3. Oxygenation of pectoral skeletal muscle fibres in perciform fishes from different thermal environments normalised to similar conditions

\begin{tabular}{lccc}
\hline & & & Minimum \\
Species & Region & $\begin{array}{c}P_{\mathrm{O}_{2}} \\
(\mathrm{kPa})\end{array}$ & $\begin{array}{c}\mathrm{P}_{2} \\
(\mathrm{kPa})\end{array}$ \\
\hline Trematomus newnesi & Ant & $1.43 \pm 1.31$ & 0 \\
Lepidonotothen nudifrons & Ant & $1.16 \pm 1.35$ & 0 \\
Notothenia coriiceps & Ant & $1.33 \pm 1.33$ & 0 \\
Chaenocephalus aceratus & Ant & $0.45 \pm 1.31$ & 0 \\
Paranotothenia magellanica & Sub & $3.24 \pm 0.84$ & 2.15 \\
Eleginops maclovinus & Sub & $2.56 \pm 1.04$ & 1.23 \\
Patagonotothen tessellata & Sub & $2.53 \pm 1.04$ & 1.26 \\
Champsocephalus esox & Sub & $2.40 \pm 1.31$ & 1.06 \\
Lithognathus mormyrus & Med & $5.38 \pm 0.18$ & 5.17 \\
Coris julius & Med & $4.45 \pm 0.45$ & 3.94
\end{tabular}

Ant, Antarctic; Sub, sub-Antarctic; Med, Mediterranean; $K r$, Krogh's diffusion coefficient.

Input variables: temperature, $10^{\circ} \mathrm{C}$; fibre radius, $22.8 \mu \mathrm{m}$; capillary radius, $3.1 \mu \mathrm{m} ; K r=0.4$ for nototheniids and $K r=0.5$ for channichthyids; mitochondrial volume density, $V_{\mathrm{v}}$ (mit,f), and capillary-to-fibre ratio, C:F, as in Table 1.

Values are means \pm S.D. ( $N=961$ grid points $)$.

viscosity (Wells et al., 1990; Egginton and Rankin, 1998). However, across this range of vessel size, the boundary conditions for oxygen efflux are sufficiently different to cause a higher oxygen supply along the larger vessel circumference, leading to a smaller decrease in oxygen tension away from the vessel. At the appropriate capillary radius and permeability values, mean $P_{\mathrm{O}_{2}}$ in channichthyid slow fibres is modest, but it would be dangerously low $(0.52 \pm 1.22 \mathrm{kPa})$ if their capillaries were similar in size to those of the nototheniids. Indeed, for the minimum $P_{\mathrm{O}_{2}}$ to be above zero would require a $50 \%$ greater capillary radius, approaching $6 \mu \mathrm{m}$ (in which case, mean $P_{\mathrm{O}_{2}}$ would be $1.99 \pm 1.46 \mathrm{kPa}$ ), whereas if capillary radius were half that observed, we predict a fivefold reduction in oxygen tension (to $0.23 \pm 0.87 \mathrm{kPa}$ ). The model therefore indicates that icefish utilise capillaries of the minimum radius required for efficient oxygen delivery, suggesting that larger-diameter capillaries may incur maintenance costs that impose an upper size limit. We may assume that there is a mechanical cost involved in maintaining a microcirculation of greater bore than that optimised for transport and exchange functions in most other vertebrate groups. Hence, it would appear that the combined influences on peripheral oxygen transport allow icefish to utilise capillaries of a minimum radius commensurate with maintaining the required level of oxidative metabolism.

\section{Concluding remarks}

Antarctic notothenioids have large diameter fibres and a high mitochondrial content, which tend to decrease mean $P_{\mathrm{O}_{2}}$. At the maximal fibre $\dot{M}_{\mathrm{O}_{2}}$, capillary supply is unlikely to maintain 
a high $P_{\mathrm{O}_{2}}$ for all species: hypoxaemia is likely to develop in the pectoral muscle fibres of the icefish Chaenocephalus aceratus, which lacks respiratory pigments, while red-blooded nototheniids potentially have little problem in maintaining a high $P_{\mathrm{O}_{2}}$. Sub-Antarctic notothenioids have a similar muscle fine structure to those caught within the Antarctic Convergence, resulting in a relatively high mean $P_{\mathrm{O}_{2}}$ in redblooded species. Even within the large diameter fibres of the icefish Champsocephalus esox, $P_{\mathrm{O}_{2}}$ exceeds $1 \mathrm{kPa}$ at winter temperatures $\left(4^{\circ} \mathrm{C}\right)$, although oxidative metabolism is predicted to be impaired at the summer maximum $\left(10^{\circ} \mathrm{C}\right)$. At the other thermal extreme, related Mediterranean perciform species have a negligible drop in intracellular $P_{\mathrm{O}_{2}}$ across a fibre, and these fibres are of similar size to those of Trematomus newnesi from the Antarctic. We tentatively identify a hierarchy of importance for the various influences on muscle fibre oxygenation as follows: temperature, capillary number, fibre size, $V \mathrm{v}(\mathrm{mit}, \mathrm{f})$, diffusion constant, fibre composition and capillary radius. No one factor can explain the observed differences among species, e.g. cold-adapted fish still have a low $\mathrm{P}_{\mathrm{O}_{2}}$ at $10{ }^{\circ} \mathrm{C}$ when normalised for fibre radius, as a result of high mitochondrial content and low capillary supply (Table 3).

These data suggest that, within a single phylogenetic group, integrative structural adaptations potentially enable a similar degree of tissue oxygenation over a $20^{\circ} \mathrm{C}$ range of environmental temperature in the nototheniids that is overwhelmed by the lack of respiratory pigments in the channichthyids. Importantly, $P_{\mathrm{O}_{2}}$ does not correlate with either activity pattern or ecological niche since high values are found at both thermal extremes of the perciform habitat.

Supported by grants from the Natural Environment Research Council of the UK (GR3/10522 to S.E. and GR3/12550 to I.A.J.) and the British Council - Antorchas Foundation (Argentina Project 13817/4 to J.C.). We are most grateful to the British Antarctic Survey, Cambridge and Dr Bruno Tota, Naples for supplying fish.

\section{References}

Acierno, R., Agnisola, C., Tota, B. and Sidell, B. D. (1997). Myoglobin enhances cardiac performance in antarctic icefish species that express the protein. Am. J. Physiol. 273, R100-R106.

Archer, S. D. and Johnston, I. A. (1987). Kinematics of labriform and subcarangiform swimming in the Antarctic fish Notothenia neglecta. J. Exp. Biol. 143, 195-210.

Archer, S. D. and Johnston, I. A. (1991). Density of cristae and distribution of mitochondria in the slow muscle fibres of Antarctic fish. Physiol. Zool. 64, 242-258.

Battram, J. C. and Johnston, I. A. (1991). Muscle growth in the Antarctic teleost, Notothenia neglecta (Nybelin). Antarct. Sci. 3, 29-33.

Bossen, E. J., Sommer, J. R. and Waugh, R. A. (1978). Comparative stereology of the mouse and finch left ventricle. Tissue Cell 10, 773-784.

Clarke, A. and Johnston, I. A. (1996). Evolution and adaptive radiation of Antarctic fishes. Trends Ecol. Evol. 11, 212-218.

Cruz-Orive, L. M. and Weibel, E. R. (1981). Sampling designs for stereology. J. Microsc. 122, 235-257.
Desaulniers, N., Moerland, T. S. and Sidell, B. D. (1996). High lipid content enhances the rate of oxygen diffusion through fish skeletal muscle. Am. J. Physiol. 27, R42-R47.

Eastman, J. (1993). Antarctic Fish Biology. New York: Academic Press. 322pp.

Egginton, S. (1990). Morphometric analysis of tissue capillary supply. In Vertebrate Gas Exchange from Environment to Cell. Advances in Comparative and Environmental Physiology, vol. 6 (ed. R. G. Boutilier), pp. 73-141. Berlin: Springer Verlag.

Egginton, S. (1994). Stress response in two Antarctic teleosts (Chaenocephalus aceratus Lönnberg and Notothenia coriiceps Richardson) following capture and surgery. J. Comp. Physiol. B 164, 482-491.

Egginton, S. (1998). Anatomical adaptations for peripheral oxygen transport at high and low temperatures. S. Afr. J. Zool. 33, 119-128.

Egginton, S. and Rankin, J. C. (1998). Vascular adaptations for a low pressure/high flow blood supply to locomotory muscles of icefish. In Antarctic Fishes: A Biological Overview (ed. G. DiPrisco, A. Clarke and E. Pisano), pp. 185-195. Berlin: Springer-Verlag.

Egginton, S. and Sidell, B. D. (1989). Thermal acclimation induces adaptive changes in subcellular structure of fish skeletal muscle. Am. J. Physiol. 256, R1-R9.

Fernandez, D. A., Calvo, J., Franklin, C. E. and Johnston, I. A. (2000). Muscle fibre types and size distribution in sub-Antarctic notothenioid fishes. J. Fish Biol. 56, 1295-1311.

Forster, M. E., Franklin, C. E., Taylor, H. H. and Davison, W. D. (1987). The aerobic scope of an Antarctic fish, Pagothenia borchgrevinki and its significance for metabolic cold adaptation. Polar Biol. 8, 155-159.

Holeton, G. F. (1972). Gas exchange in fish with and without hemoglobin. Respir. Physiol. 14, 142-150.

Hoofd, L. and Egginton, S. (1997). The possible role of intracellular lipid in oxygen delivery to fish skeletal muscle. Respir. Physiol. 107, 191-202.

Hoppeler, H., Kayar, S. R., Claassen, H., Uhlmann, E. and Karas, R. H. (1987). Adaptive variation in the mammalian respiratory system in relation to energetic demand. III. Skeletal muscles: setting the demand for oxygen. Respir. Physiol. 69, 27-46.

Johnston, I. A. (1987). Respiratory characteristics of muscle fibres in a fish (Chaenocephalus aceratus) that lacks haem pigments. J. Exp. Biol. 133, 415-428.

Johnston, I. A., Calvo, J., Guderley, H., Fernandez, D. and Palmer, L. (1998). Latitudinal variation in the abundance and oxidative capacities of muscle mitochondria in perciform fishes. J. Exp. Biol. 201, 1-12.

Johnston, I. A. and Camm, J. P. (1987). Muscle structure and differentiation in pelagic and demersal stages of the Antarctic teleost Notothenia neglecta. Mar. Biol. 94, 183-190.

Johnston, I. A., Clarke, A. and Ward, P. (1991). Temperature and metabolic rate in sedentary fish from the Antarctic, North Sea and Indo-west Pacific ocean. Mar. Biol. 109, 191-195.

Johnston, I. A., Guderley, H., Franklin, C. E., Crockford, T. and Kamunde, C. (1994). Are mitochondria subject to evolutionary temperature adaptation? J. Exp. Biol. 195, 293-306.

Johnston, I. A. and Maitland, B. (1980). Temperature acclimation in crucian carp: a morphometric analysis of muscle fibre ultrastructure. J. Fish Biol. 17, $113-125$.

Kilarski, W., Smialowska, E. and Friedhuber, A. (1982). Histological analysis of fibers in myotomes of Antarctic fish. 2. Morphometry of muscle fibers and capillaries. Z. Mikrosk. Anat. Forsch. 96, 791-801.

Kock, K.-H. (1992). Antarctic Fish and Fisheries. Cambridge: Cambridge University Press. $359 \mathrm{pp}$.

Longmuir, I. S. (1980). Channels of oxygen transport from blood to mitochondria. Adv. Physiol. Sci. 25, 19-22.

Moylan, T. J. and Sidell, B. D. (2000). Concentrations of myoglobin and myoglobin mRNA in heart ventricles from Antarctic fishes. J. Exp. Biol. 203, 1277-1286.

Somero, G. N. (1995). Proteins and temperature. Annu. Rev. Physiol. 57, 43-68.

Wells, R. M. (1987). Respiration of Antarctic fish from McMurdo Sound. Comp. Biochem. Physiol. 88A, 417-424.

Wells, R. M. G., Macdonald, J. A. and DiPrisco, G. (1990). Thin-blooded Antarctic fishes: a rheological comparison of the haemoglobin-free icefishes Chionodraco katleenae and Cryodraco antarcticus with a red blooded nototheniid, Pagothenia bernacchii. J. Fish Biol. 36, 595-609. 